は非常に良く集中的になり，曲げ破損に関して木材は等方性体に関する敍上の理論に萧る。

2,3 の樹種について単一集中荷重と全等布荷重の場合に著者が行つた実験に上れば，その結果は理諭と良く合 ふことを認める。断面の大きな梁などでは異方性を考慮して木取ることは困難となるので, 勢ひ所謂積層材の方 法が問題となり，この場合矢張り敍上の理論に乗せて差支ないものと思ふ。

少 2,3 の重要と思はれる点を挙げると

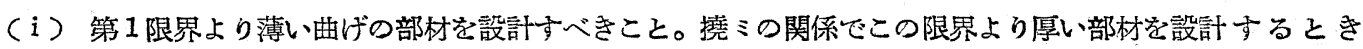
は，法則に從つて許容㐫力度を逓減すべきこと。且つこの第 1 限界は材料により又荷重によつて特異な ること。

(ii) 普通に行はれてるる中央単一集中荷重によつて得られた許容応力度を揭ぐる方法は，第 1 限界以上の厚 さをもつ梁の場合では設計上如何なる指示をも与光得ないものであるといふこと。著者は寧ろ独立強度 $\sigma_{\mathrm{t}}, \sigma_{\mathrm{c}}, \tau_{\mathrm{b}}$ と破損法則とを揭ぐる力法の合理的なるを採りたいと思う。

（iii） 連行静荷重の場合は等値等布荷重に換算して全等布荷重に関する理論を適用して近似的に可なること。 しかしマれは今少しく検討の要があろら。

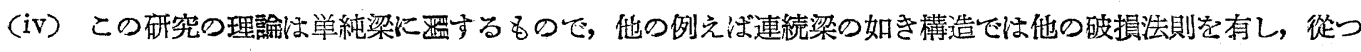
て許容応力度子変るものと思ふ。

（v）材料の剪断応力破損に関しては，直ちに剪断主応力の仮設を想起させるが，剪断主応力は繊維方向に対 して傾斜し，この方向に於ける木材の剪断抵抗は非常に大きい。從つてこの材料の剪断曲げ破損の決定 的応力要素は, 絾維に沿ふ絶対最大剪断応力であると見られ, この事実は単一集中荷重 (位置を変化せ しめたる) 及び全等布荷重等による著者のこれまでの実験結果が，良く本研究の理䄖と合致することに よつても確認され得るのである。

\title{
垂直荷重を受ける変断面矩形版の解法
}

正員成岡 昌 夫*

\section{ON THE SOLUTION OF A VERTICALLY LOADED RECTANGULAR PLATE WITH VARIABLE FLEXURAL RIGIDITY}

\author{
Masao Naruoka, C.E.Member
}

\begin{abstract}
Synopsis On the assumption that a rectangular slab is devided into a proper number of sections and the rigidity in the same section is approximately uniform, the author worked out a method of approximate calculation of the deflection, bending moment, etc. by using the slope deflection formula which had been introduced by him for a rectangular slab under vertical load.
\end{abstract}

要旨 変断面矩形版を適当な数に分割し,汾割された区間內に於ては剖度を近似的に一定と見做すととに依り， さきに著者の誘導した垂直荷重を受ける矩形版に対する撓角法公式を用いて, 撓ミ, 曲げモーメント等を近似的に 計算する方法を逝べたものである。

1. 緒 言

変断面矩形版の撓ミの微分方程式は次の通りである。

$$
\begin{aligned}
& N \Delta \Delta w+2 \frac{\partial N}{\partial x} \cdot \frac{\partial}{\partial x} \Delta w+2 \frac{\partial N}{\partial y} \cdot \frac{\partial}{\partial y} \cdot \Delta w+\Delta N \cdot \Delta w \\
& -(1-\nu)\left\{\frac{\partial^{2} N}{\partial x^{2}} \cdot \frac{\partial^{2} w}{\partial y^{2}}-2 \frac{\partial^{2} N}{\partial x \partial y} \cdot \frac{\partial^{2} w}{\partial x \partial y}+\frac{\partial^{2} N}{\partial y^{2}} \cdot \frac{\partial^{2} w}{\partial x^{2}}\right\}=p(x, y)
\end{aligned}
$$

但し $\Delta=\frac{\partial^{2}}{\partial x^{2}}+\frac{\partial^{2}}{\partial y^{2}}, \quad N=$ 版剛度 
(1) 式心 $N(x, y), p(x, y)$ が任意の函数なる場合结一般に解けない。從来円版に関しては色々取扱われて来た

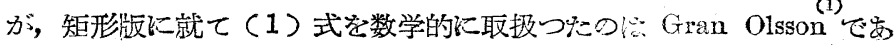
る。彼は 図一1 の如き周辺単純支持矩形版にて $N=N_{0}+N_{1} x, p=p^{0}$ $\left(1+\frac{N_{1}}{N_{0}} x\right)$ なる特殊の場合に就て, Exponential Integral を用いて解 いているが，例えば $N, p$ が $x$ のの函数であるにしても上式と異なつ

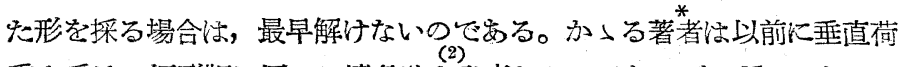
重を受ける短形版に用いる撓角法を発表したのであるが， $N, p$ が $x$ の みの函数で焉る場合には撓角法を応用し，变断面版の撓ミ及び曲げモー メントを容易に見出すととが出来る。

この方法に從えば，版岡度，荷重が同じ方向に如何なる変化をしてい ても, 単に多元一次方程式を解くことに体つて, 容易に所望の值を求め

図-1

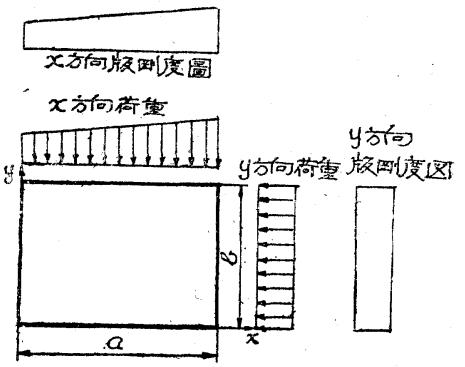

ることが出来，なんら高等な函数わ必要としない。又矩形版を細かく分割するに從つていくらでも精密值に近ず け得るのである。

\section{2. 基本公式}

図一2 に於て版は，y=0 及び $b$ にて単純吝持とし， $x=0$ 及 $x=a$ に於ける境界条件 図-2 を次の如く表わすものとする。

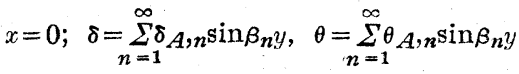

$$
\begin{aligned}
& M=\sum_{n=1}^{\infty} M_{A B, n_{n}} \sin \beta_{n} y, \quad V=\sum_{n=1}^{\infty} V_{A B,{ }_{n}} \sin \beta_{n} y \\
& x=a ; \quad \delta=\sum_{n=1}^{\infty} \delta_{B}, n_{n} \sin \beta_{n} y, \quad \theta=\sum_{n=1}^{\infty} \theta_{B},{ }_{n} \sin \beta_{n} y \\
& M=-\sum_{n=1}^{\infty} M_{B A, n_{n}} \sin \beta_{n} y, \quad V=\sum_{n=1}^{\infty} V_{B A, n_{n}} \sin \beta_{n} y
\end{aligned}
$$

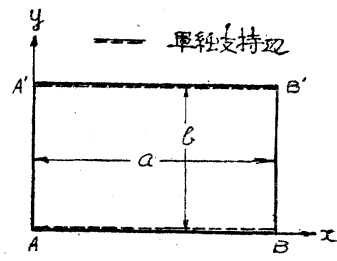

但ᄂ $\beta_{n}=\frac{n \pi}{b}$

前著に依り

$$
\left.\begin{array}{l}
M_{A B, n}=N \beta_{n} \frac{1}{c^{2}\left(\alpha_{n}\right)-s^{2}\left(\alpha_{n}\right)}\left[c\left(\alpha_{n}\right) \theta_{A, n}+s\left(\alpha_{n}\right) \theta_{B, n}-\beta_{n}\left\{i\left(\alpha_{n}\right) \delta_{B, n}-j\left(\alpha_{n}\right) \delta_{A, n}\right\}\right]+C_{A B, n} \\
M_{B A, n}=N \beta_{n} \frac{1}{c^{2}\left(\alpha_{n}\right)-s^{2}\left(\alpha_{n}\right)}\left[s\left(\alpha_{n}\right) \theta_{A, n}+c\left(\alpha_{n}\right) \theta_{B}, n-\beta_{n}\left\{j\left(\alpha_{n}\right) \delta_{B, n}-i\left(\alpha_{n}\right) \delta_{A, n}\right\}\right]+C_{B A, n} \\
V_{A B, n}=-N \beta_{n}{ }^{2} \frac{1}{c^{2}\left(\alpha_{n}\right)-s^{2}\left(\alpha_{n}\right)}\left[j\left(\alpha_{n}\right) \theta_{A, n}+i\left(\alpha_{n}\right) \theta_{B, n}-\beta_{n}\left\{g\left(\alpha_{n}\right) \delta_{B}, n-h\left(\alpha_{n}\right) \delta_{A, n}\right\}\right]+D_{A B, n} \\
V_{B A, n}=-N \beta_{n}^{2} \frac{1}{c^{2}\left(\alpha_{n}\right)-s^{2}\left(\alpha_{n}\right)}\left[i\left(\alpha_{n}\right) \theta_{A, n}+j\left(\alpha_{n}\right) \theta_{B},,_{n}-\beta_{n}\left\{h\left(\alpha_{n}\right) \delta_{B, n}-g\left(\alpha_{n}\right) \delta_{A}, n\right\}\right]+D_{B A, n}
\end{array}\right\}
$$

又 $\mathrm{BB}^{\prime}$ 辺にて $M_{B A}=0$ ならば

$$
\begin{aligned}
& M_{A B, n}=N \beta_{n} \frac{1}{c^{2}\left(\alpha_{n}\right)-s^{2}\left(\alpha_{n}\right)}\left[\frac{c^{2}\left(\alpha_{n}\right)-s^{2}\left(\alpha_{n}\right)}{c\left(\boldsymbol{\alpha}_{n}\right)} \theta_{A, n}-\beta_{n}\left\{i^{\prime}\left(\alpha_{n}\right) \delta_{B, n}-j^{\prime}\left(\alpha_{n}\right) \delta_{A, n}\right\}\right]+H_{A B, n} \\
& V_{A B, n}=-N \beta^{2} \frac{1}{c^{2}\left(\boldsymbol{\alpha}_{n}\right)-s^{2}\left(\boldsymbol{\alpha}_{n}\right)}\left[j^{\prime}\left(\boldsymbol{\alpha}_{n}\right) \theta_{A, n}-\beta_{n}\left\{g^{\prime}\left(\boldsymbol{\alpha}_{n}\right) \delta_{B}, n_{n}-h^{\prime}\left(\boldsymbol{\alpha}_{n}\right) \delta_{A}, n_{n}\right\}\right]+K_{A B, n}
\end{aligned}
$$

$\mathrm{AA}^{\prime}$ 辺比て $M_{A B}=0$ ならば

但ᄂ

$$
\left.\begin{array}{l}
M_{B A, n}=N \beta_{n} \frac{1}{c^{2}\left(\boldsymbol{\alpha}_{n}\right)-s^{2}\left(\boldsymbol{\alpha}_{n}\right)}\left[\frac{c^{2}\left(\boldsymbol{\alpha}_{n}\right)-s^{2}\left(\boldsymbol{\alpha}_{n}\right)}{c\left(\boldsymbol{\alpha}_{n}\right)} \theta_{B, n}-\beta_{n}\left\{j^{\prime}\left(\boldsymbol{\alpha}_{n}\right) \delta_{B, n}-i^{\prime}\left(\boldsymbol{\alpha}_{n}\right) \delta_{A, n}\right\}\right]+H_{B A, n} \\
V_{B A, n}=N \beta^{2}{ }_{n} \frac{1}{c^{2}\left(\boldsymbol{\alpha}_{n}\right)-s^{2}\left(\boldsymbol{\alpha}_{n}\right)}\left[j^{\prime}\left(\boldsymbol{\alpha}_{n}\right) \theta_{B, n}-\beta_{n}\left\{h^{\prime}\left(\boldsymbol{\alpha}_{n}\right) \delta_{B}, \dot{n}-g^{\prime}\left(\boldsymbol{\alpha}_{n}\right) \delta_{A, n}\right\}\right]+K_{B A, n}
\end{array}\right\}
$$

$$
\begin{aligned}
& \alpha_{n}=\frac{n \pi a}{b} \text { として } \frac{1}{c}=\frac{2 \sinh ^{2} \alpha_{n}}{\sinh \alpha_{n} \cosh \alpha_{n}-\alpha_{n}} \\
& \frac{e}{c^{2}-s^{2}}=\frac{2\left(\sinh \alpha_{n} \cosh \alpha_{n}-\alpha_{n}\right)}{\sinh ^{2} \alpha_{n}-\alpha_{n}^{2}}, \frac{s}{c^{2}-s^{2}}=\frac{2\left(\alpha_{n} \cosh \alpha_{n}-\sinh \alpha_{n}\right)}{\sinh ^{2} \alpha_{n}-\alpha_{n}^{2}}
\end{aligned}
$$




$$
\begin{aligned}
& \frac{i}{c^{2}-s^{2}}=\frac{2 \alpha_{n} \sinh \alpha_{n}}{\sinh ^{2} \alpha_{n}-\alpha_{n}^{2}}, \quad \frac{j}{c^{2}-s^{2}}=\frac{(1-\nu) \alpha_{n}^{2}+(1+\nu) \sinh ^{2} \alpha_{n}}{\sinh ^{2} \alpha_{n}-\alpha_{n}^{2}} \\
& \frac{g}{c^{2}-s^{2}}=\frac{2\left(\alpha_{n} \cosh \alpha_{n}+\sinh \alpha_{n}\right)}{\sinh ^{2} \alpha_{n}-\alpha_{n}^{2}{ }^{*}}, \quad \frac{h}{c^{2}-s^{2}}=\frac{2\left(\sinh \alpha_{n} \cosh \alpha_{n}+\alpha_{n}\right)}{\sinh ^{2} \alpha_{n}-\alpha_{n}^{2}} \\
& i^{\prime}=i-\frac{s}{c} j, \quad j^{\prime}=j-\frac{s}{c} i, \quad g^{\prime}=g-\frac{i}{c} j \quad, \quad h^{\prime}=h-\frac{i}{c} i
\end{aligned}
$$

$C, D, H, K$ は荷重項ともい5べきもので等分布荷重の場合には次のよ5になる。

$$
\begin{aligned}
& C_{A B, n}=-C_{B A, n}=-\frac{4 p b^{2}}{\pi^{3} n^{3}} \frac{\sinh \alpha_{n}-\alpha_{n}}{\sinh \alpha_{n} \alpha_{n}}=-\frac{4 p b^{2}}{\pi^{3} n^{3}} \cdot C \\
& H_{A B, n}=-H_{B A, n}=C_{A B, n}-\frac{s}{c} C_{B A, n}=-\frac{4 p b^{2}}{\pi^{3} n^{3}} H, K_{A B, n}=-K_{B A, n}=D_{A B, n} \\
& +\frac{i}{c} \beta_{n} C_{B A, n}=\frac{4 p b}{\pi^{2} n^{2}} K \\
& \frac{1}{c}, \frac{c}{c^{2}-s^{2}}, \frac{s}{c^{2}-s^{2}}, \frac{i}{c^{2}-s^{2}} \text {, } \\
& \frac{j}{c^{2}-s^{2}}, \frac{g}{c^{2}-s^{2}}, \frac{h}{c^{2}-s^{2}}, \frac{j^{\prime}}{c^{2}-s^{2}}, \\
& \frac{h^{\prime}}{c^{2}-s^{2}}, C, D, H \text { 及 } K \text { の值を } n=1 \\
& \text { として } \frac{a}{b} \text { の種ふの值に対し求める } \\
& \text { と表一1の如くなる。な呿こつでは } \\
& \nu=0.16 \text { に採つてある。 }
\end{aligned}
$$$$
D_{A B, n}=-D_{B A, n}=\frac{4 p b}{\pi^{2} n^{2}} \frac{2\left(\cosh \alpha_{n}-1\right)}{\sinh \alpha_{n}+\alpha_{n}}=\frac{4 p b}{\pi^{2} n^{2}} \cdot D
$$

\section{3. 琶角法に依る変断面矩形版の解法}

図一了 以撓多及曲げモーメントを求めよらとする変断面矩形版を示す。版の辺 長老 $a, b$ とし， $y=0$ 文 $b$ にて単純支持とする。今この版を図のよ5に $n$ 等分す ると， $n$ 等分された区間の版岡度は近似的に直線変化をなするのと見做すことが 出来る。且つ各区間の両端の版剛度の平均学採つてその区間の平均版剛度とす る。斯くして求めた平均の版剛度を夫々の区間の一様な版剛度とする版を考えよ 万。この版に於ては版剛度は階段的に変化することになる。

撓角法に依る変断面版の艧法は求めよ 5 とする変断面版を上記のような階段状 の版に置き換え，この階段状版に就て計算を進めるのである。徉つて計算の結果

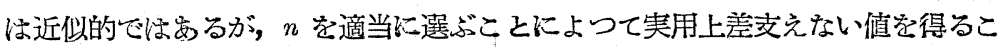
とが出来，又必要ならば象際の版にいくらても近ずけることが出来る。

次に荷重が版岡度の変化している方向に漸変している場合は，版剛度を階段状 に置き捔えるに対応して荷重も階段状荷重に置き换え，各区間に於ては等分布荷 重と見做して計算を進めるとよい。

置き換えられた階段状版に図一4のよ5に各分割点に $0,1,2 \cdots m \cdots n$ の番号を つけ,な拜 $N_{m}=k_{m} N_{c}(m=0,1,2 \cdots n-1)$ とする。

今 $x=0$ 及 $a$ にて単純支持としこの般が垂淔荷重学受けて彎曲を起しててる 場合，各分割点に就いて曲げモーメント及び反力の釣合条件式を求めると次の(7), (8) 式となる。

$$
\begin{aligned}
& e_{1}{ }^{\prime} \theta_{1}+f_{1} \theta_{2} \quad-t^{\prime}{ }_{1} \delta_{1}-d_{1} \delta_{2} \quad=\frac{-1}{\beta \cdot N_{c}}\left(H_{1,0}+C_{1,2}\right)
\end{aligned}
$$

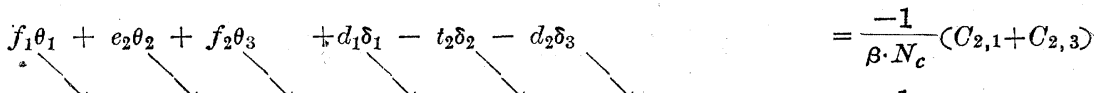

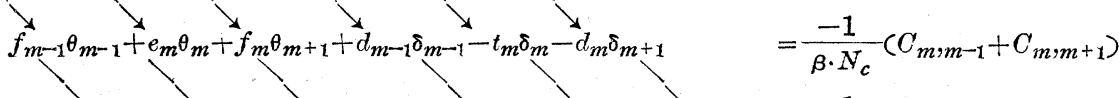

$$
\begin{aligned}
& \searrow_{f_{n-3} \theta_{n-3}+e_{n-2} \theta_{n-2} f_{n-2} \theta_{n-1}+d_{n-3} \delta_{n-3}-t_{n-2} \delta_{n-2}-d_{n-2} \delta_{n-1}}^{\searrow}=\frac{-1}{\beta \cdot N_{c}}\left(C_{n-2}^{\gamma}, n-3+C_{n-2}, n-1\right) \\
& f_{n-2} \theta_{n-2}+e^{\prime}{ }_{n-1} \theta_{n-1} \\
& +d_{n-2} \delta_{n-2}-t^{\prime}{ }_{n-1} \delta_{n-1}=\frac{-1}{\beta \cdot N_{c}}\left(C_{n-1, n-2}+H_{n-1}, n\right)
\end{aligned}
$$




$$
\begin{aligned}
& d^{\prime}{ }_{1} \theta_{1}-t_{1} \theta_{2} \quad-u^{\prime}{ }_{1} \delta_{1}+v_{1} \delta_{2} \quad=\frac{1}{\beta^{2} N_{c}}\left(K_{1,0}-D_{1,2}\right)
\end{aligned}
$$

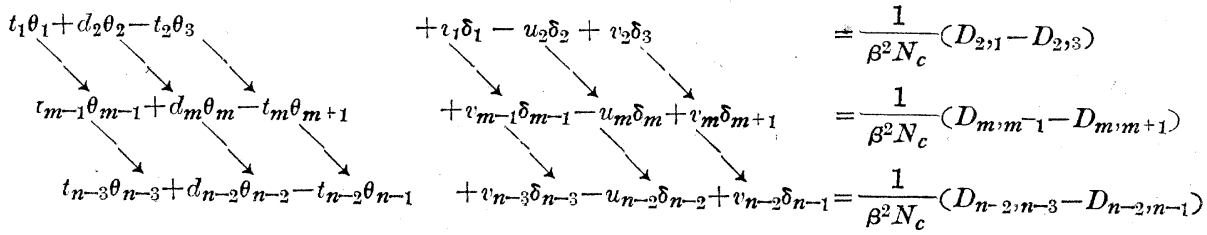

$$
\begin{aligned}
& t_{n-2} \theta_{n-2}+d_{n-1}^{\prime} \theta_{n-1} \quad+v_{n \rightarrow 2} \delta_{n-2}-u_{n-1}^{\prime} \delta_{n-1}=\frac{1}{\beta^{2} N_{c}}\left(D_{n-1, n-2}-K_{n-1, n}\right)
\end{aligned}
$$

但し

$$
\begin{aligned}
& e_{m}=k_{m-1} \frac{c_{m-1}}{c_{m}^{2}-1-s_{m}^{2}-1}+k_{m} \frac{c_{m}}{c_{m}^{2}-s_{m}^{2}}, \quad f_{m}=k_{m} \frac{s_{m}}{c_{m}^{2}-s_{m}^{2}} \\
& e_{1}^{\prime}=k_{0} \frac{1}{c_{0}}+k_{1} \frac{c_{1}}{c_{1}^{2} s_{1}^{2}}, \quad e_{n-1}^{\prime}=k_{n-2} \frac{c_{n-2}}{c_{n}^{2}-2-s_{n-2}^{2}}+k_{n-1} \frac{1}{c_{n-1}} \\
& d_{m}=k_{m-1} \frac{j_{m-1}}{c_{m}^{2}-1-s_{m}^{2}-1}-k_{m} \frac{j_{m}}{c_{m}^{2}-s_{m}^{2}}, \quad t_{m}=k_{m} \frac{i_{m}}{c_{m}^{2}-s_{m}^{2}} \\
& d_{1}^{\prime}=k_{0} \frac{j_{0}^{\prime}}{c_{0}^{2}-s_{0}^{2}}-k_{1} \frac{j_{1}}{c_{1}^{2}-s_{1}^{2}}, \quad d_{n-1}^{\prime}=k_{n-2} \frac{j_{n-2}}{c_{n}^{2}-2-s_{n}^{2}-2}-k_{n-1} \frac{j_{n-1}^{\prime}}{c_{n-1}^{2}-s_{n-1}^{2}} \\
& u_{m}=k_{m-1} \frac{h_{m-1}}{c_{m^{2}-1}-s_{m}^{2}-1}+k_{m} \frac{h_{m}}{c_{m}^{2}-s_{m}^{2}}, \quad v_{m}=k_{m} \frac{g_{m}}{c_{m}^{2}-s_{m}^{2}} \\
& u_{1}^{\prime}=k_{0} \frac{h_{0}^{\prime}}{c_{0}^{2}-s_{0}^{2}}+k_{1} \frac{h_{1}}{c_{1}^{2}-s_{1}^{2}}, \quad u_{n-1}^{\prime}=k_{n-2} \frac{h_{n-2}}{c_{n-2}^{2}-s_{n-2}^{2}}+k_{n-1} \frac{h_{n-1}^{\prime}}{c_{n-1}^{2}-s_{n-1}^{2}}
\end{aligned}
$$

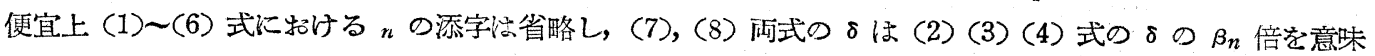
するものとする。

上の多元 1 次万程式を解いて $\delta$ と $\theta$ が求められ, 從つて (2) 式より $M_{x}$ の值が求められる。剆ら各分割点 の $\delta$ 及び $M_{x}$ の值が求められたわけである。次に任意の点の $\delta$ 及び $M_{x}, M_{y}$ はラーメンの場合と同じ考え方 で, 4 辺単純支持の場合の $\delta$ 及び $M_{x}, M_{y}$ と, 相対する 2 辺にて単純支持され他の 2 辺に上で求めた $\delta$ 及び $M_{x}$ を受ける場合の $\delta$ 及び $M_{x}, M_{y}$ を組合せることに依つて求められる。

\section{4. 計算例}

図一5 の如さ正方形版が 4 辺単純支持され全面に等分荷重を受ける。版剛度は $x$ 图-5 方向に於てのみ 1 次的に変化しているものとし, 一端で $N_{0}$, 他端で $8 N_{0}$ とする。 この場合の $y=\frac{a}{2}$ に於ける撓ミを求めよ5。

撓刍法を適用するため図の如く $y$ 軸に平行なる線で 5 筞分する。各区間の平均剛 度は $1.7 N_{0}, 3.1 N_{0} 4.5 N_{0}, 5.9 N_{0}$ 及び $7.3 N_{0}$ となり, 從つて $N_{c}=N_{0}$ として $k_{0}=$ $1.7, k_{1}=3.1, k_{2}=4.5, k_{3}=5.9$ 及び $k_{4}=7.3$ となる。又等分布荷重であるから $n=1$, $3,5 \cdots$ 場合を考慮すればよい。從つて必要なる諸函数を表一1 より求めると表一2 の通りである。例えば $n-3$ に対しては表一 1 に示す $n=1, \frac{a}{b}=0.6$ の值を用い るのである。

\section{表-2}

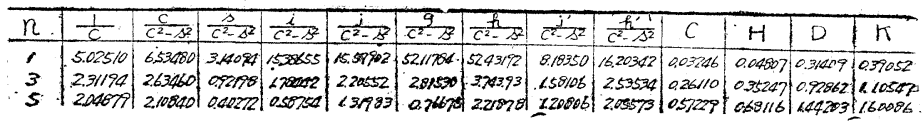

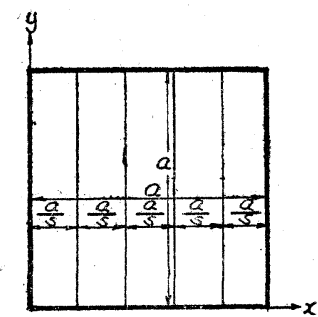

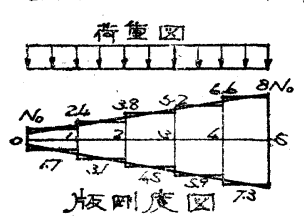

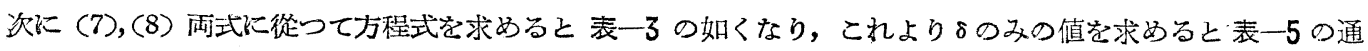
らである。從つて $y=\frac{a}{2}$ に於ける $\delta$ の值は次の如く求められる。

$$
\delta_{1}=\frac{4 p a^{4}}{\pi^{5} N_{0}}\left\{\frac{1}{15} 0.05791-\frac{1}{3^{5}} 0.27075+\frac{1}{5^{5}} 0.37346\right\}=0.05692 \frac{4 p a^{4}}{\pi^{5} N_{0}}
$$




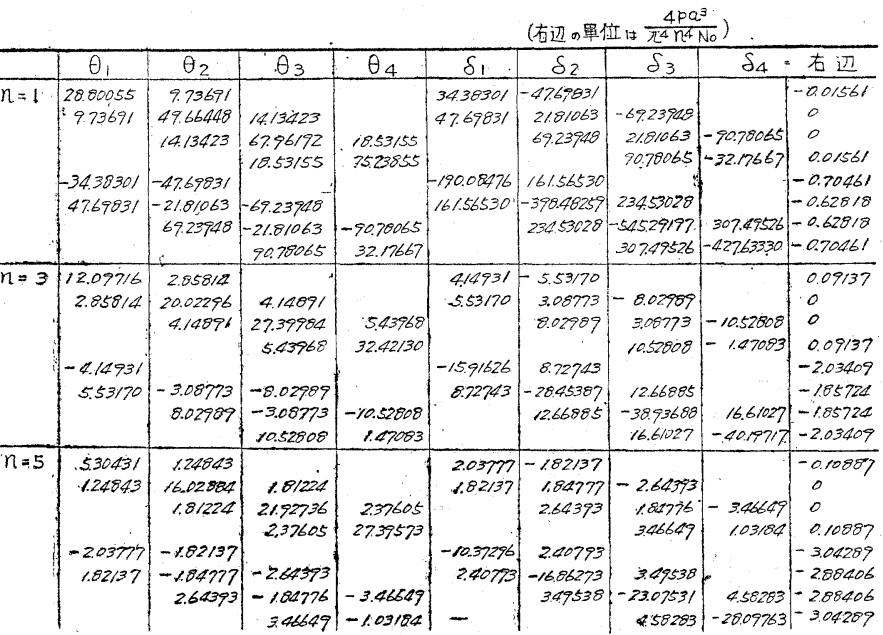

\begin{tabular}{l|l|l|l}
\multicolumn{3}{c}{ 表-4 (單位 $\left.\frac{4 p a^{4}}{\pi^{5} n^{5} N_{0}}\right)$} \\
\hline$\delta$ & $n=1$ & $n=3$ & $n=5$ \\
\hline$n$ & & & \\
\hline$\delta_{1}$ & 0.05791 & 0.27075 & 0.37346 \\
$\delta_{2}$ & 0.07596 & 0.24943 & 0.26447 \\
$\delta_{3}$ & 0.06613 & 0.18719 & 0.19394 \\
$\delta_{4}$ & 0.03792 & 0.11715 & 0.13822
\end{tabular}

$$
\delta_{2}=0.07501 \frac{4 p a^{4}}{\pi^{5} N_{0}} \quad \delta_{3}=0.06542 \frac{4 p a^{4}}{\pi^{5} N_{0}} \quad \delta_{4}=0.03748 \frac{4 p a^{4}}{\pi^{5} N_{0}}
$$

上に得た值を $45 N_{0}$ (左右网端の岡度の平 均值) を一定の版剛度とする正方形版の撓 ミ と比較すると表一5のよ5になる。

但し $\delta_{2} .5$ の值 0.07309 は 4 個の函数值によ

り Lagrange の内插式に依り求めたもので ある。

$$
\text { 表一 } \left.5 \text { (単位 } \frac{4 p a^{4}}{\pi^{5} N_{0}}\right)
$$

\begin{tabular}{c|c|c|c|c|c}
\hline & $\delta_{1}$ & $\delta_{2}$ & $\delta_{2 \cdot 5}$ & $\delta_{3}$ & $\delta_{4}$ \\
\hline 変断面版 & 0.05692 & 0.07501 & 0.07309 & 0.06542 & 0.03748 \\
均一断面版 & 0.04026 & 0.06695 & 0.07079 & 0.06695 & 0.04529
\end{tabular}

次に同じ版に於て荷重強度が版剛度に比例する場合, 師ら $x$ 方向に於てのみ 1 一次的に変化し， 1 端に於て $p_{0}$ ，他端にて $\delta p_{0}$ となる場合を解いててよう。

撓角撓度法公式の荷重項け等分布荷重の場合に対して求めて 岕るのて，等変分布荷重には適用し得ない。從つて版㴊度を階 段状に考えたと同様に荷重強度も階段状に考え, 各区間内に於 ては荷重強度も一定とする。郎ち各区間の等分布荷重強度は

$1.7 p_{0}, 3.1 p_{0}, 4.5 p_{0} 5.9 p_{0}$ 及 $7.3 p_{0}$ となる。

この場合の釣合条件式の左辺は表一3 と同一であつて，右辺 のみ次のよ5に変えるとよい。

表一3 の右辺の值

\begin{tabular}{c|r|r}
\hline$n=1$ & \multicolumn{1}{c|}{$n=3$} & \multicolumn{1}{c}{$n=5$} \\
\hline 0.01891 & 0.21021 & 0.61613 \\
0.04544 & 0.36554 & 0.80121 \\
0.04544 & 0.36554 & 0.80121 \\
0.15940 & 1.03254 & 1.59596 \\
-1.63756 & -4.75802 & -7.19176 \\
-2.38708 & -7.05751 & -10.95943 \\
-3.26654 & -9.65765 & -14.99711 \\
-4.70393 & -13.54879 & -20.19426
\end{tabular}

この多元一次方程式を解いて $\theta, \delta$ を得, 更に (2) 式より $M_{x}$ の值を

\section{表一 6}

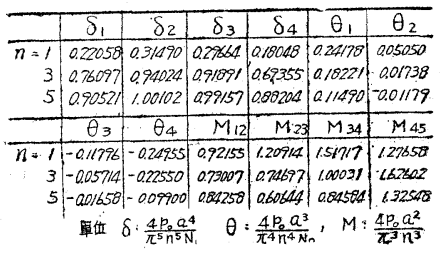

求めると表一6のよ5になる。

從つて $y=\frac{a}{2}$ 於ける $\delta$ 及 $M_{x}$ の值は前と同様にして求められ, その 結果を示すと表一7のよ5である。

表一 7

\begin{tabular}{l|l|l|l|l|l|l|l}
\hline$\delta_{1}$ & $\delta_{2}$ & $\delta_{3}$ & $\delta_{4}$ & $M_{12}$ & $M_{23}$ & $M_{34}$ & $M_{45}$ \\
\hline
\end{tabular}

\begin{tabular}{l|l|l|l|l|l|l|l|l|}
\hline 0.21774 & 0.31135 & 0.29317 & 0.17791 & 0.90125 & 1.18633 & 1.48689 & 1.22696
\end{tabular} 単位 $\delta ; \frac{4 p_{0} a^{4}}{\pi^{5} N_{0}}, \quad M ; \frac{4 p_{0} a^{2}}{\pi^{3}}$ 
この結果を図に示せば 図一6の通りで岕る。図中点線は撓角法にて求めた 值, 岀線は Gran Olsson が Exponential Integral を用いて正確汇解いを值 である。分割数を 10 にすれば更に精密な值を得られること沿勿諭で岀るが， 極めて大まかな分割の場合に於ても，撓角法に依る解法正触に比して大して 蕗色を認めない。

\title{
5. 結 言
}

以上示しま如く撓角法に依る解法仙，版岡度及荷重強度が $x$ 又は $y$ はのいう れふのみの函数である場合に蛿，それらが如何なる函数形を採らちとも，いず れの場合にも適用される。文なんら高等なる函数表を必要としない点も便利て 岕る。但し計算式誘導に於ける相対する2辺学純支持の仮定に㣘束されること 以免れない。的ち本計算例の場合では版剛度, 荷重強度の一定なる方向に於て は単純支持でなければ，このう法は使用出来ない欠点がある。目下周辺の交持 条件に拘束されない㩞角法について研究を進めているので他日発表したいと考 えている。

な特本文学草するに当つては京大教授小西博士の御指導を賜り，計算には同

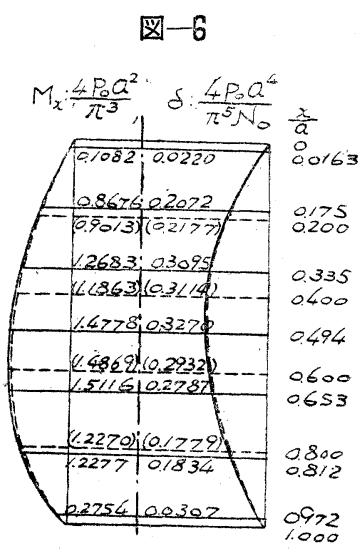

实線; G.Olssonの精密部算 卓線: 著者的近似㖕算 土木工学教室職員石原清忠君の助力を仰いで。こつに附記して厚く感謝の意を表す次第である。

引用交献

(1) Gran Olsson: Ing-Archiv; 5(1934) 5.363.

（2）成岡昌夫：撓角撓度法に依る1方向連続版の解法; 土木学会誌に近く発表の予定

(3) Timoshenko; Theory of Plates and Shells; p.127

\section{PAPER LOCATION についての 2, 3 の基礎的 問題の図式解法について}

\author{
正員 大 島 太市*
}

\author{
ON THE DIAGRAMATIC SOLUTION OF THE SOME \\ FUNDAMENTAL PROBREMS ON THE PAPER LOCATION
}

\author{
Taichi Oshima, C.E. Member
}

\begin{abstract}
Synopsis; Proper plans can hardly be formulated in accordance with paper location unless the location is carried out on a definite principle. Moreover, a systematic paper plan is necessary for increasing the utility of the diagrams.

In this paper, solutions of the problems arising in connection with the determination of the shortest route are given as examples, and methods are described with respect to typical topographic conditions, of graphical determination of the shortest route on a definite gradient and of the shortest route with the length of line being given.
\end{abstract}

要 旨 Poper Location を行万場合，一定の方針のもとでなすのでなければ，適正な計画を行らことは仲々

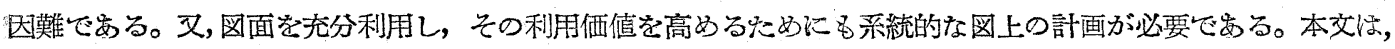
その 1 例として路線の最短なものを決定する時に, 起つてくる闍題, 例穴ばある一定の勾配の下に最短路をき める場合，又は，路線長を括さえて最短路をきめる場合などの問題を代表的な地形について図式に求める方法に ついて吟昧したものである。 